\title{
How to Create Change Readiness? The Change Interpretation Matters
}

\author{
Jinzhao Deng ${ }^{1, *}$, Richard Deng ${ }^{2}$, Lei Huang ${ }^{3}$, Jianghao $\mathrm{Gao}^{4}$ \\ ${ }^{1}$ College of Business Administration, Hubei University of Economics, Wuhan, China \\ ${ }^{2}$ Department of Economics, University of Ottawa, Ottawa, Canada \\ ${ }^{3}$ College of Business Administration, Hubei University of Economics, Wuhan, China \\ ${ }^{4}$ Economics and Management Academy, China University of Geosciences (Wuhan), Wuhan, China \\ *Corresponding author. Email: dengjinzhao@hbue.edu.cn
}

\begin{abstract}
That how employees interpret change plays a critical role in organizational change. To offer an understanding of the relationship between organizational change strategies and employees' readiness for change from a social cognitive perspective, a model is initially built based on relevant literature reviewed and then data are collected from 22 organizations in China and Zimbabwe. A sample of 132 individuals is analysed, and hypothesized relationships are investigated using AMOS software. The findings support an integrated perspective in which both change management strategies and employees' change interpretations shape change readiness. Furthermore, the findings show that employees with high change communication, participation and perceptions of principal support tend to exhibit high levels of change readiness and that change interpretation plays a partial mediating role between change strategies and change readiness. In the last part of paper the theoretical contribution and practical implication of this study are discussed
\end{abstract}

Keywords: Organizational Change, Change Readiness, Change Management Strategy, Interpretation of Change.

\section{INTRODUCTION}

Successful change efforts are critical for organizational survival and growth. Most change management researchers in the literature have formulated some frameworks and methodologies to comprehend the change and the ways to manage it. Even though the specific causes for different failures of organizational change are still unknown at present, the influence of employees' response to organizational change on the implementation of change and even the success of the change cannot be ignored due to it plays a substantial part in change process.

Tompson and Hunt (1996) draw attention to the cognitive processes involved in changing attitudes. They discovered that when there are dysfunctional cognitive processes, employees will resist the change. Therefore, understanding the cognitive processes that influence change readiness is important and can help in the organizational change implementation success.

Most past researchers have defined the concept of change readiness from cognitive perspective, but they have failed to study the contributions of cognition in the creation of change readiness. The purpose of this research is to explore and describe the way that organizational change strategies affect employees' readiness for change from social cognitive perspective.

Literature Review

Employees' reactions towards organizational change

The literature describes that as members of an organization, employees may be primarily affected by any sort of change in the organization, and their responses might be negative or positive [1].Many factors are found to have close relations with implementation of effective organizational changes, and change readiness in different levels of an organization is considered as a key cognitive forerunner of change adoption [2]. Armenakis' definition of change readiness was extended by Holt and his co-operators by adding what employees think about the organizational change, including if and to what extent the change could bring about positive results to them and to the organization [3]. 


\section{Change communication}

The change message is found to be the main vehicle of promoting readiness for change [2]. The quality of communication and the information received by employees subsequently could help clarify the justification for the necessity of change, diminish the undesired results brought by change uncertainty and facilitate the creation of employees' change readiness. We hypothesize therefore the following:

Hypothesis 1: Adequate change communication has a positive effect on change readiness.

\section{Change participation}

Participation refers to employees being allowed to partake in making decisions and solving change-related problems. There are lots of benefits of getting employees involved in planning change and implementation, and many researchers have highlighted these benefits in their studies[4]. Moreover, if employees have a high level of empowered perception in organizational change, they are more likely to adjust their values and behaviors according to the needs of organizational change strategies [5]. We then have the following hypothesis:

Hypothesis 2: Perceived active change participation has a positive effect on change readiness.

Principal/organizational support

Principal support is the opinion that the organization, change drivers and superiors demonstrate that they are committed to the change and affirmatively support the organizational change efforts and are strongly motivated to make the change successful [6]. When employees have a feeling or perception that their organization or superiors are providing adequate and continuing support in form of resources and information at the beginning of the change or in the process of the change, they will experience change positively and form positive evaluations [7]. Therefore we have the hypothesis as follows:

Hypothesis 3: Perceived principal support has a positive effect on change readiness.

Hypotheses 1, 2 and 3 describe the relationship between change strategies and readiness for change. Based on the above analysis, we believe that what employees think about change such as personal valence and change appropriateness might have important effects on the relationship between the two.

Valence is the perceived personal benefits that someone may expect during organizational change initiative [8]. That is, if an individual views the organizational change in some way that satisfies his self-interest, in most cases, he will then be inclined to accept and support the change.

Appropriateness is the description of whether the proposed change initiative is the correct one for the organizational needs [8]. However, the employees would evaluate whether the change solution is the right one or even the best one for the benefit of the organization.

Focusing on change management through a sociocognitive approach indicates that positive change interpretations of employees can minimize resistance to change after change intervention, and appropriate change management strategies are key elements in creation of favorable change interpretation. Therefore, this study intends to investigate how these positive evaluations and interpretations affect the creation of a change readiness. Hence, the following hypothesis is suggested:

Hypothesis 4: Employees' interpretations of change have mediating effects on the relationship between change management strategies (change communication, change participation, and principal support) and change readiness.

\section{METHOD}

\subsection{Research Sample}

A quantitative method was used to test the hypotheses. Data were gathered from organizations in China and Zimbabwe that are undergoing transformational changes. The sample diversity was emphasized, and a questionnaire was developed that included questions relating to the factors that can lead to the creation of readiness during organizational change.

We selected the participating organizations through convenience sampling. An email was sent to the Human Resources Departments of the organizations to explain the primary purposes of the research. Then, we asked the responders who expressed their willingness to take part in the study to give our survey links (that were also sent by email) to their employees and also to provide a brief instruction on how to use it, while the other survey questionnaires were distributed as hard copies. We finally got a sample package included 132 employees who volunteered from the 18 organizations that were going through changes.

\subsection{Measurement Scales}

The English and Chinese versions of the questionnaire included 5-point scales ranging from 1 to 5 and were used in Zimbabwe and China respectively.

A three-item scale was used to measure change communication. To measure change participation, a three-item scale was used to capture the extent to which employees perceived that they were taking part in the change process. One of them is "changes are always discussed with all people involved." Principal support was measured by the three-item scale .One of items is "Our leaders have encouraged us to embrace this change." we measure change interpretation by a 6 -item scale. 
Example of items is "I believe that the organization would benefit from the change" Change readiness was measured by the tri-dimensional model of emotional, cognitive, and intentional readiness. Items include "I have a good feeling about the change project" The study controlled other factors, such as gender, tenure and age, in the analysis.

\subsection{Data Analysis}

We tested the accuracy of the data by investigating the missing data, outliers, linearity, multi-collinearity and normality before the analyses of the participants' responses. Then, AMOS 17.0 and SPSS 20.0 were used to test the hypotheses.

\section{RESULTS}

We examined the dimensionality of the change interpretation. The examination gained a 2 -factor result, which explained $69 \%$ of the total variance in the items. Fit indices indicated a good model fit. The model of change readiness showed a valid 3-factor solution and each of the items was retained. The measurement model in this study included 5 variables. The overall measurement model demonstrated a acceptable fitness to the observed data. The conclusion can be drawn that the 5 factors model had a better fit to the measurement data with an acceptable validity.

We conducted examination on our hypothesized model according to the above measurement model through path loading analysis. The model indicates that change strategies were positively associated with change readiness. Therefore, Hypotheses 1, 2, and 3 were fully supported by the data. Then we provided a more precise and rigorous analysis of the mediating effects hypothesis by calculating the change interpretation's indirect effects using the bootstrapping approach. The results show that the indirect effect of change communication after standardization on change readiness through change interpretation was positive at the 0.05 level $(.11, \mathrm{CI}=$ $[.05, .24], \mathrm{p}<.05)$. Furthermore, on standardization, the indirect effects of participation in change and principal support on readiness for change through interpretation of change were also positive at the 0.05 level (.14, $\mathrm{CI}=[.06, .22]$ and.19, $\mathrm{CI}=[.12, .28])$. Zero was far from these selected confidence intervals $(\mathrm{CI}=95 \%)$. Therefore, the outcomes of the analysis revealed that change interpretation has partial mediating effects on the relationship between change strategies and change readiness. It can be concluded that hypothesis 4 was further supported by the data.

\section{DISCUSSION}

Change management strategies have been discussed in the literature and have been regarded as critical factors in the process of achieving successful organization change. This study tried to move a further step to examine the role of change interpretation in creation of employees' change readiness through conducting different change strategies in Zimbabwean and Chinese organizations.

In the first place, as expected, this research found that the perceived adequacy of communication on change information, change participation, and principal support were positively associated with employees' readiness for change. The findings support the conclusions achieved in previous research that addressed strong relations between different change management strategies and change readiness $[9,10]$. It is reasonable to conclude that change communication with employees acts a significant role that can not be ignored in creating change readiness before the change initiative's implementation and during it. Meanwhile, employees who have more opportunities to participate in the change effort were more likely to be motivated to put additional endeavour into the process of change implementation and make more self-adjustments according to the needs of change [11].

Furthermore, this study showed that change interpretation had partial mediating effects on the relationship between change management strategies and readiness. Previous researchers have seldom focused on the crucial role of change management strategies in fulfilling the success of organizational change from employees' appraisals of change.

\section{CONCLUSION}

Taken together, the findings of this paper support an integrated perspective in which both change management strategies and employees' change interpretations shape change readiness. Furthermore, the findings show that employees with high change communication, change participation and perceptions of principal support tend to exhibit high levels of change readiness and that change interpretation plays a partial mediating role between change strategies and change readiness.

Theoretical and practical implication

The paper highlights the crucial issues regarding the reasons why it is difficult to successfully achieve the goals of organizational change. It makes a substantial contribution to the theoretical literature that debate show to improve organizational change practices and management effectiveness. This work adds to the present literature regarding change readiness in an organizational context by suggesting that individuals' cognitive processes can create positive evaluations of change [10] and facilitate the development of change readiness.

For practitioners, creating change readiness through a range of management strategies to make organizational change successful is the main goal. This research shows that it depends not only on what the change drivers do in the process of change (choosing what kinds of change strategies) to achieve successful organizational change, 
but also on how employees interpret the change (change interpretation). Furthermore, the employees' understandings and beliefs on change have an explicit effect on how change management strategies chosen by organization impact employees' readiness for organizational change. This conclusion could help us in establishing change policies, such as how to launch change activities in the first stage of change and how to implement a structural change communication system, which would facilitate change success by creating an organizational environment that is positive and that supports change.

\section{RECOMMENDATIONS}

Some limitations inevitably exist in this research. The first limitation is the relatively small size of the sample. Second, we collected data from individuals in organizations. Although self-reported data are quite common in management research, it may raise concerns on potential biases. Thus, we would encourage future researchers to include larger samples with more respondents to perform a longitudinal design, to take multi-method approaches to collecting data to increase the robustness of the results.

Whether it would be a kind of process or state, the antecedents of change readiness merit further research due to its close relationship with change effectiveness. Other organizational factors (change culture, climate, systems, etc.) and contextual factors (leadership, interaction, LMX, etc.) may impact change readiness, and researchers can consider these variables in future investigations.

\section{ACKNOWLEDGMENTS}

The paper is supported by Humanities and Social Sciences project of the Ministry of Education of China (20YJA630010) and the National Natural Science Foundation of China (71472060)

\section{REFERENCES}

[1] Alexander, S. (2004). Becoming empowered: organization change in a telecom company. The International Journal of Human Resource Management, 15(8), 1445-1462.

[2] Amis, J. M. \& Aissaoui, R. (2013). Readiness for change: An institutional perspective. Journal for Change Management, 13(1), 69-95.

[3] Appelbaum, S. T., St-pierre, N. \& Glavas, W. (1998). Strategic organisational change: The role of leadership, learning, motivation and productivity. Management Decision, 36(5), 289-301.

[4] Armenakis, A. A., Harris, S. G., \& Mossholder, K. W. (1993). Creating readiness for organizational change. Human Relations, 46(6), 681-703.

[5] Armenakis, A. A. \& Harris, S. G. (2002). Crafting a change message to create transformational readiness. Journal of Organizational Change Management, 15(2), 169-183.

[6] Armenakis, A. A., Harris, S. G., Cole, M. S., Fillmer, J. L., \& Self, D. R. (2007). A top management team's reactions to organizational transformation: the diagnostic benefits of five key change sentiments. Journal of Change Management, 7(3), 273 - 290.

[7] Bouckenooghe, D. and Devos, G. (2007, January). Psychological Change Climate as a Crucial Catalyst of Readiness for Change: Dominance Analysis. Paper presented at Academy of Management Annual Meeting Proceedings, DOI: 10.5465/AMBPP.2008.33661178.

[8] Bommer, W. H., Rich, G. A., \& Rubin, R. S. (2005). Changing attitudes about change: longitudinal effects of transformational leader behavior on employee cynicism about organizational change. Journal of Organizational Behavior, 26(7).

[9] Bovey, W. H. \& Hede, A. (2001). Resistance to organizational change: The role of cognitive and affective processes. Leadership \& Organization Development Journal, 22(8), 372-382.

[10] Caldwell, R. (2005) Things fall apart? Discourses on agency and change in organizations. Human Relations, 58(1), 83-114.

[11] Choi, M., \& Ruona, W. E. A. (2011). Individual readiness for organizational change and its implications for human resource and organizational development. Human Resource Development Review, 10(1), 46-73. 